\title{
A TEORIA DA CAUSALIDADE IMAGINÁRIA NA FILOSOFIA DE HUME
}

\author{
Alexandre Arbex Valadares* \\ alexarbex@gmail.com
}

RESUMO O presente trabalho aborda a concepção de causalidade apresentada pelo filósofo escocês David Hume no Tratado da natureza humana (TNH) e propõe, como argumento central, que a ideia de relação causal deriva de uma impressão reflexiva e toma a forma de uma crença imaginária cujo objeto é uma conjunção constante. Começando por analisar os conceitos de impressões e ideias, sobre os quais Hume elabora sua teoria da percepção, o texto explora, em seguida, os fundamentos do processo de associação de ideias, do qual a noção de causalidade é um modo; um breve estudo dos efeitos políticos decorrentes de uma concepção de causalidade assentada na crença e nos hábitos de percepção põe termo a este artigo.

Palavras-chave Hume; Causalidade; Imaginação.

ABSTRACT This work analyses the theory of causality presented by the Scottish philosopher David Hume in his Treatise on Human Nature. It proposes, as a central argument, that the idea of causal relation comes from a reflexive impression and assumes the form of an imaginary belief, whose object is a constant conjunction. Starting by analyzing the concepts of impressions and ideas, over which Hume elaborates his theory of perception, this text explores the basis of the process of association of ideas, and identifies the notion of causality as a mode of it. A brief study of the political effects of

\footnotetext{
* Mestre em Ciência Política pelo Instituto Universitário de Pesquisas do Rio de Janeiro (IUPERJ) e doutorando em Filosofia pela Universidade Federal do Rio de Janeiro (UFRJ). Artigo recebido em dez.

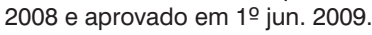

KRITERION, Belo Horizonte, no 119, Jun./2009, p. 251-268. 
such a conception of causality, based on belief and perception habits, gives a conclusion to this article.

\section{Keywords Hume; Causality; Imagination.}

\section{I}

Hume inicia o Tratado da natureza humana com uma proposição conceitual que distingue as percepções da mente humana em duas classes fundamentais: impressões e ideias. A rigor, essa distinção não presume uma dicotomia, nem estabelece entre seus termos diferenças antagônicas de natureza. A divisão das percepções entre impressões e ideias é antes intensiva que qualitativa, isto é, diz respeito às variações de intensidade ou aos respectivos graus de vividez $\mathrm{e}$ força que se devem atribuir a cada tipo de percepção. As impressões são mais vívidas, penetram mais violentamente em nosso pensamento em sua primeira aparição à alma, e abrangem as sensações e as paixões. E, como na ordem de aparição das percepções à mente as impressões sempre antecedem as ideias, estas, objetos de operação de nosso intelecto, manifestam apenas as imagens embaciadas e mortiças que nos ficam dessas impressões distanciadas no espaço e no tempo. Impressões e ideias concordam em natureza, concernem a uma mesma percepção, considerada em dois momentos distintos de sua presença na mente. As ideias derivam das impressões, compartilham sua substância, refletem-nas e representam-nas: elas são as marcas dessas impressões dissipadas no fluxo de percepções que constitui a mente humana.

As ideias, para Hume, são imagens fracas das impressões, elementos secundários na ordem das percepções e que, por essa razão, não poderiam ser consideradas inatas. Se, por outro lado, se entende por inato o que é original ou não copiado de nenhuma percepção anterior, então as impressões podem ser ditas inatas, porque precedem as ideias no curso habitual das percepções. Desse ponto de vista, a diferença dos estatutos atribuídos a impressões e ideias decorre de que, para Hume, o mundo do ser, das existências, coincide com o mundo das aparências, o mundo tal como o percebemos. Ademais, como para Berkeley, cuja máxima "ser é ser percebido" costuma encimar os textos dedicados à sua obra nos manuais de filosofia, também para Hume a ideia de existência relaciona-se à percepção: ${ }^{1}$ não há impressão ou ideia que não seja concebida como existente; a ideia de existência é rigorosamente idêntica à ideia daquilo que concebemos 
existir, ou seja, à ideia da própria percepção. Essa identidade é sumarizada por Hume na forma de uma tautologia: qualquer ideia que quisermos formar será a ideia de um ser, e a ideia de um ser será qualquer ideia que quisermos formar. Na realidade, afirma Hume, jamais avançamos um passo além de nós mesmos nem podemos conceber nenhuma existência diversa das percepções que se nos apresentam dentro dos estreitos limites das sensações.

Ideias e impressões subdividem-se ainda em duas outras modalidades: podem denominar-se simples, se não comportam discrição nem separação, ou complexas, se é possível distingui-las em partes menores. A noção de ideias e impressões simples, ou da indivisibilidade de impressões e ideias, define, segundo a expressão de Deleuze, ${ }^{2}$ o "atomismo espiritual" de Hume. A mente, composta de percepções simples, é uma coleção de átomos, elementos irredutíveis uns aos outros, ideias e impressões elementares que se correspondem mutuamente, com predominância das últimas sobre as primeiras. A percepção complexa de uma maçã, segundo o modelo de Hume, decompõe-se nas impressões mais simples de seu aroma, seu sabor e sua cor. Berkeley, na introdução do seu Tratado dos princípios do conhecimento humano, alude à mesma imagem, notando que certa cor, forma e consistência, seguidas de certo sabor e aroma percebidos em conjunto, designam uma coisa singular chamada "maçã".

As partes do objeto, ou da percepção que no-lo representa, definem-se de acordo com seu modo de aparição no tempo e no espaço. A ideia de espaço, de extensão, concerne à contiguidade regular dos pontos sensíveis que faz nossa percepção oscilar naturalmente de uns para outros; a ideia de tempo, por sua vez, reflete na mente a sucessão perceptível desses pontos na série ininterrupta de percepções que nos torna presente a noção de duração. A experiência desenvolve-se nesse movimento sucessivo de ideias e impressões separáveis e qualitativamente diferentes, tendo em vista que todas as nossas percepções distintas aludem a existências distintas.

Mas esse princípio da diferença, norma empírica por excelência segundo Deleuze, ${ }^{3}$ dá lugar a um paradoxo filosófico. Ora, não temos uma impressão simples do tempo: percebemo-lo apenas indiretamente pela sucessão dos objetos em mudança. As ideias das partes indivisíveis do tempo devem ser, então, preenchidas de existência real, sensível. A percepção mais simples, unidade indivisível da mente, constitui o seu dado invariante. Essa fração elementar da natureza não é um ponto físico, mas um ponto sensível. Hume 
sustenta que, para toda ideia simples, há uma impressão simples correspondente, e toda impressão simples remete a uma ideia simples correlata. Como, além disso, ideias e impressões complexas se formam a partir das simples, conclui-se por força que, entre essas duas espécies de percepção, vigora uma equivalência de natureza. A anterioridade das impressões simples em relação às ideias simples, na ordem da aparência - a própria ordem do ser, para Hume - , atesta que as segundas são causadas pelas primeiras. É, porém, impossível experimentar isoladamente uma impressão simples: não podemos, por exemplo, experimentar o átomo, visto que este, como diz Hume, não tem extensão. De que modo, então, é possível conceber uma ideia simples sem a derivar da impressão simples que a causaria? E como podemos atribuir existência a uma impressão simples?

Dá-se, porém, que nossa mente não se detém jamais na consideração de uma impressão ou de uma ideia absolutamente singular. Isto significa que a mente opera com impressões e ideias complexas e que as ideias simples só existem nela já associadas umas às outras. A imaginação pode entremeá-las em variadas combinações, mas nunca as conceber separadamente, porque tende, por certas propriedades originais de sua natureza, a associar as ideias segundo determinadas relações. A imaginação passa de uma a outra ideia irresistivelmente, e prescinde, nesse movimento, do concurso do raciocínio; a associação de ideias na imaginação é pré-cognitiva. Essa explicação do conceito de ideia simples na filosofia de Hume é análoga à que se pode oferecer acerca da noção de "corpos mais simples" na física de Spinoza: ${ }^{4}$ para este, com efeito, os corpos simples, que integram a composição dos corpos complexos, somente podem ser concebidos em infinitudes, e nunca individualmente, isto é, como átomos isolados. A ser procedente a comparação, não parece ser justa a definição dada por Deleuze segundo a qual, para Hume, a mente humana seria uma "coleção de átomos": na verdade, ela não se apresenta como estrutura molecular de percepções simples, mas como feixe de ideias e impressões que se associam e desassociam sucessivamente. Cada impressão ou cada ideia pode extinguir-se ou renovar-se na mente ao acaso das percepções. Identificar a mente a uma coleção de átomos significa defini-la pela sua estrutura e pelos seus elementos, ao passo que Hume, considerando-a um feixe de ideias e impressões associadas segundo determinados princípios, define-a, antes, pelas suas relações. O reconhecimento da ideia simples como unidade invariante da mente não exprime a constância e uniformidade da atividade da 
imaginação: o que confere a esta sua estabilidade por assim dizer atemporal não é a associação das mesmas ideias simples nas mesmas ideias complexas, mas, antes, as relações ou princípios através dos quais essas ideias simples se associam umas às outras.

Como o mecanismo de associação de ideias opera, em última instância, com ideias simples, o efeito de sua atividade é a produção de ideias complexas. Se a associação de ideias na imaginação se realizasse ao acaso e se estivesse no poder de cada um criar a seu talante os objetos de suas cogitações, não haveria qualquer regularidade no curso dos assuntos humanos e apenas por exceção se poderiam encontrar as mesmas ideias complexas ou as mesmas composições de ideias simples em épocas e lugares diferentes. Segundo Hume, porém, no registro histórico das experiências dos povos, as paixões humanas parecem manifestar-se sob formas regulares, reiteradas em padrões afetivos que, ao andar dos tempos, se conservam idênticos em sua tendência geral. $\mathrm{O}$ fato de ser impossível imaginar, por exemplo, que um dia haja existido homens indiferentes ao poder e à beleza ilustra essa regularidade que permite a Hume atribuir à imaginação princípios operatórios imutáveis, intrínsecos à sua natureza, e suscetíveis de definir o elenco de qualidades associativas a partir das quais se formam as ideias complexas. Apesar de ser reputada uma faculdade livre do pensamento, capaz de ultrapassar em suas criações os próprios modelos da natureza, a imaginação encontra, nas suas leis de operação, os seus limites; de resto, a própria noção de impressões e ideias simples assinala essa determinação: se nos é dado reduzir as ideias e impressões a percepções elementares, então o princípio de associação da imaginação opera com um conjunto finito de ideias que, embora possam combinar-se indefinidamente, não chegam a formar um universo infinito de possibilidades.

Para Hume, as três qualidades associativas da imaginação são a semelhança, a contiguidade e a causalidade. A associação das ideias, que preside à composição das ideias complexas na imaginação, é uma propriedade original da natureza humana e consiste numa função essencial da mente. É impossível que a mente se atenha a uma única ideia simples, como é impossível que o corpo seja afetado por uma única impressão simples. Se uma ideia se faz presente à imaginação, qualquer outra, unida a ela por relações de semelhança, contiguidade ou causalidade, segue-lhe naturalmente. A regularidade do mecanismo de associação de ideias explica por que a imaginação opera com um repertório mais ou menos constante de ideias complexas. As relações de ideias atendem antes a essa qualidade operatória que ao conteúdo formal das ideias mesmas: a relação que a imaginação estabelece entre duas ideias é exterior a estas, e não pode ser deduzida a partir da consideração de nenhuma 
delas em particular. A associação de ideias é uma regra da imaginação, e não um exercício livre de suas faculdades. Temos tanto poder sobre as associações que se operam na imaginação como sobre os movimentos dos órgãos ou as oscilações da sentimentalidade. O mecanismo de associação de ideias dá-se a conhecer apenas por seus efeitos na imaginação, e são os efeitos dessas operações associativas que constituem os dados originais de um espírito cuja ação se desenvolve independentemente da consciência que temos dela.

\section{II}

Hume $^{5}$ considera a associação de ideias uma determinação inata da natureza humana. As ideias derivam das impressões, e estas assinalam os limites existenciais que separam a natureza humana desse mundo exterior a cujos objetos não se tem acesso senão por via de percepções. As impressões que nos afetam e formam as ideias em nossa imaginação aparecem-nos como objetos de percepção particulares, desvinculados dos objetos externos a que somos determinados a relacioná-los. Esses objetos são percebidos apenas pelas modificações que produzem na nossa sensibilidade, e nunca na sua natureza objetiva. Nosso conhecimento do mundo circunstante, cujos limites confinam com os de nossa sensibilidade, é puramente alucinatório. Ele envolve a crença original em uma realidade exterior: supomos todo um mundo de objetos reais com base apenas nas percepções que temos deles, isto é, com base nas percepções que temos de nosso próprio corpo e a partir das quais derivamos as ideias de imaginação que representam em nós esse exterior povoado.

As ideias são-nos dadas como imagens de impressões imediatas, mas podemos formar, a partir dessas ideias primárias, ideias secundárias — ideias de ideias - que introduzem na imaginação outra qualidade de percepção: a imaginação opera uma alucinação em segundo grau das ideias em relação às impressões imediatas. Por esse movimento, as ideias abstraem suas impressões originais e assumem a forma de efeitos espontâneos da mente. As impressões produzem imagens de si mesmas — as ideias —, e estas, apresentadas à mente como novos objetos de percepção, imprimem nela novas ideias, que reproduzem as primeiras, tal como estas reproduzem as impressões primárias. O princípio segundo o qual todas as ideias derivam de impressões permanece válido, mas agora é preciso ajuntar-lhe outra modalidade e discernir entre impressões de sensação e impressões de reflexão. As primeiras nascem imediatamente na mente a partir de causas ignoradas que excedem no espaço 
e no tempo o alcance da percepção, e concernem às percepções sensíveis dos objetos exteriores que se nos deparam à sorte. Por sua vez, as impressões de reflexão nascem mediatamente na mente e derivam das ideias primárias: são impressões internas, causadas pela imagem de uma impressão de sensação, que, demorando-se na alma após o desaparecimento do objeto exterior a que se relaciona, produz uma nova impressão, de desejo ou aversão — uma paixão em relação à imagem desse objeto.

A impressão de sensação, dado imediato da experiência, produz um duplo efeito: por um lado, uma ideia relativa a esta impressão, isto é, a ideia que constitui a continuação dessa impressão na mente e cuja representação não supera o conteúdo inteligível da sensação original; essa ideia produz, por outro lado, uma nova impressão na mente, que a apreende como um novo objeto que se choca contra o feixe de percepções que forma a composição atual da imaginação. Essa nova impressão supera o conteúdo da primeira e excede os dados da experiência. Isto significa dizer que, na imaginação, podem-se formar ideias complexas, produzidas por associação, que não remetem a impressões de sensação correspondentes nem se prendem aos objetos da experiência, sobretudo porque esta última não pode fornecer a impressão distinta de uma relação. Ainda que a imaginação torne presentes à mente os objetos que ela apreende sob dada relação, ela não pode formar, apenas a partir deles, uma imagem dessa relação.

O que determina a forma da associação de ideias na imaginação é a impressão de reflexão ou paixão causada pelo choque entre a ideia primária imediatamente derivada de uma impressão sensível e o conjunto das percepções presentes na imaginação em dada atualidade. As impressões de reflexão e o mecanismo de associação de ideias explicam de que maneira se podem apresentar à imaginação ideias complexas a que não se pode ligar nenhuma impressão sensível correspondente. Para empregar uma analogia informal, podemos dizer que comumente exprimimos a sensação provocada na alma por uma impressão de reflexão quando afirmamos coisas como "tenho impressão", "tenho a vaga ideia de que tal coisa acontecerá": isto sucede quando sentimos se formar em nós algo como uma noção espontânea ou disposição íntima em relação a um objeto, e que, sem resultar de nossas ponderações, serve como o ponto de partida delas. Estamos a sentir a influência de uma impressão de reflexão quando uma paixão dirige, na imaginação, o mecanismo de associação de ideias.

A regra da associação de ideias que nos interessa aqui é a causalidade. Essa noção faz-se presente à alma quando percebemos um objeto como causa da ação ou da existência de outro. A causalidade, para Hume, não só é uma 
modalidade de operação da mente, uma relação natural pela qual duas ideias, uma introduzindo a outra, se associam na imaginação, mas constitui ainda uma relação filosófica, uma qualidade que torna passíveis de comparação os objetos implicados. Para Hume, ${ }^{6}$ todos os tipos de raciocínio consistem em comparar e em descobrir as relações entre dois objetos, estejam estes presentes ou não aos sentidos. A impressão de causalidade suscita em nós a ideia de que a ação ou a existência de um objeto é seguida ou precedida pela ação ou existência de outro. Conhecer, para Hume, é formular proposições de causalidade, mas as conexões causais são, a rigor, imateriais: não as podemos deduzir a partir da qualidade dos objetos relacionados e, portanto, não nos é dado vinculá-las, como percepções distintas, a impressões de sensação distintas. Isto significa que, se é possível formar a ideia de dois objetos distintos a partir de suas respectivas impressões ou imagens, não se pode formar uma ideia da relação causal que supomos uni-los. Esta relação não corresponde, ela própria, a um objeto exterior, mas resulta em nós de uma associação, operada na imaginação, a partir das ideias de dois objetos. Ao examinarmos um juízo causal como "a areia arde porque faz calor", verificamos que os termos da relação — "a areia arde" e "faz calor" - evocam duas impressões distintas, mas não podemos derivar a vinculação expressa pelo conectivo "porque" de uma terceira impressão, e tal conectivo é o próprio motor da associação de ideias.

A concepção humiana de causalidade contesta a suposição de que as ideias são representações das coisas. Em primeiro lugar, as representações mentais - as imagens formadas na alma — não se referem às relações nem podem representar conexões entre coisas. Ademais, uma ideia, segundo Hume, representa não uma coisa, mas uma impressão, a imagem de uma percepção dos sentidos. A razão, por sua vez, não é uma faculdade do espírito ou um princípio organizador das ideias, mas o reflexo de uma impressão na mente que pouco se distingue da própria imaginação: e a imaginação se racionaliza quando obedece à sua tendência passional, isto é, quando as ideias se associam em virtude de uma finalidade que somente a paixão pode imprimir à atividade dos homens. Os modos de associação de ideias estabelecem relações recíprocas entre elas, mas são as qualidades da paixão refletida na imaginação que definem a direção dessas relações. A forma da associação de ideias é dirigida pelas paixões, pelas impressões de reflexão; como afirma Deleuze, o homem associa ideias e se lança ao conhecimento porque tem paixões. ${ }^{7} \mathrm{E}$ 
a paixão, não a razão, que dá causa a esse movimento, e é este o motivo pelo qual a razão é e deve ser escrava da paixão.

Ao expor sua concepção de causalidade, ${ }^{8}$ Hume afirma ser universalmente reconhecida a noção de sucessão, a relação entre um anterior e um posterior que consagra a prioridade da causa sobre o efeito na ordem das aparições. Ele rejeita a tese segundo a qual a causa seria concomitante com seu efeito, visto que defendê-la seria o mesmo que postular a dissolução da sucessão causal observada no mundo e, por consequência, admitir a total aniquilação do tempo. Noutras palavras, não se poderia contestar a ideia de sucessão na ordem dos fenômenos perceptíveis sem assentir que os objetos da percepção coexistem simultaneamente, e que apenas os limites de nossa sensibilidade determinam-nos a supor que eles se seguem uns aos outros na duração. Hume não levanta a si mesmo essa objeção e logo abandona a defesa da sucessão temporal, advertindo o leitor de que a coisa não tem relevância; certamente se lhe afigurara depressa que o argumento o conduziria a uma conclusão contraditória. Em primeiro lugar, a coexistência de uma pluralidade de objetos singulares que impressionam a mente de modo simultâneo e imediato deduzse do conceito mesmo de ideias e impressões complexas. Como vimos, as impressões simples não são átomos isolados de sensação; uma maçã é, ao mesmo tempo, a impressão de sua cor, de seu aroma, de sua forma etc. Ademais, se chegamos a formar uma ideia de causalidade, presumimos que existem uma causa e um efeito, e damos a esta suposição tal forma que, quer consideremos apenas o conteúdo de cada termo da relação, quer abstraiamos ambos e ponderemos apenas a relação mesma, não poderemos conceber nem que haja uma ideia de causa sem uma ideia de efeito, nem tampouco que a relação causal possa constituir-se sem que os dois termos sejam simultaneamente presentes. Ao reivindicar a prioridade temporal da causa sobre o efeito, somos forçados a admitir que uma causa possa existir na ausência de seu efeito; mas, se a causa não produz seu efeito, ainda não é uma causa, e por isso a relação causal ainda não existe. Por outro lado, se concebemos que o efeito subsiste sem a causa, ou que a causa se extingue na produção do seu efeito, damos anuência à ideia de que o efeito, libertado da causa tão logo esta o produza, passa a existir por si só. Mas, se conjeturamos que a coisa produzida passa a existir na ausência de sua causa, como então explicar que tenha precisado dela para começar a existir? Também dessa perspectiva a causalidade é inconcebível como sucessão temporal. 
Hume logo substitui essa ideia de sucessão pela noção de conjunção, com que distingue o caráter imediato da conexão causal. Como as relações filosóficas estabelecidas pelo entendimento e pela imaginação são exteriores aos objetos relacionados, não podemos determinar a prioridade de um sobre o outro nem situar em um deles, considerado apenas na sua qualidade, o poder de causar o outro. É a constância e a uniformidade da conjunção de dois objetos que nos leva a distinguir entre eles uma relação causal. Assim, quando dois eventos se nos apresentam em conjunção constante na experiência, adquirem uma conexão tão estreita na imaginação que esta passa de um a outro sem hesitar; é dessa conjunção constante observada na experiência que advém o fundamento da ideia de necessidade. A relação de causalidade marcada por essa uniformidade, a que a recorrência de casos semelhantes empresta a força de necessidade, é tão somente uma operação da mente, alheia às qualidades dos objetos. A necessidade define-se, pois, como a determinação da mente de passar de um objeto considerado àquele que comumente o acompanha na experiência, e de inferir a existência de um a partir da do outro. A impressão de necessidade é o efeito, na mente, da impressão de uma união constante de objetos no passado, e é reiteração da imagem dessa união constante que faz a mente supor que ela se repetirá no futuro.

Em si mesmos, os objetos que a imaginação identifica às causas e aos efeitos dos fenômenos da experiência têm qualidades tão distintas entre si que, a ponderar suas diferenças, se poderia crê-los inteiramente dissociados um do outro na ordem da natureza. Jamais, senão pela experiência de sua união constante, se poderia inferir um a partir do outro. A inferência é um efeito do costume sobre a imaginação: a ideia da relação causa e efeito corresponde à ideia de objetos constantemente unidos, e a conexão necessária não traduz uma conclusão do entendimento, mas uma percepção reavivada na mente por numerosos exemplos semelhantes na experiência. Abrangendo a conjunção constante de objetos similares e a inferência de um a partir de outro, essa noção de necessidade é essencial à teoria da causalidade de Hume. O necessário caracteriza mesmo a vontade humana, que, por isso, não pode ser dita livre, isto é, aleatória e arbitrária; para Hume, podemos tirar conclusões acerca das vontades humanas com base na experiência da união constante de ações semelhantes em circunstâncias semelhantes, mas esta inferência tem lugar apenas no espírito do observador: a ação é dita necessária do ponto de vista de quem, inferindo por observação uma intenção causal, relaciona o ato ao motivo.

Poder-se-ia dizer que a ideia de causalidade não é mais que um caso de estatística, de percepção de padrões ou modelos que se reproduzem no curso 
ordinário da experiência. A conexão necessária decorre da percepção de uma conjunção constante. Essa percepção se reflete na mente como uma impressão de necessidade ou do caráter necessário do fenômeno percebido. Mas Hume questiona se uma causa é sempre necessária, como afirmam os cartesianos (sc. III, p. III, 1. I, TNH). A objeção de Hume a essa noção, segundo a qual tudo o que existe tem causa de existir, não se confunde com sua concepção própria de necessidade, fundada exclusivamente na percepção da uniformidade da conjunção constante constatada na experiência. Os cartesianos sustentam a tese de que nada pode começar a existir sem um princípio produtivo. Hume contesta essa assertiva com o seguinte argumento: como todas as ideias distintas são separáveis entre si, e como as ideias de causa e efeito são distintas, pode-se conceber, pela experiência, que um objeto não exista neste momento e se apresente, em seguida, como existente, sem que essa mudança envolva um princípio produtivo, isto é, sem que se possa deduzir uma causa de existir a partir da percepção de um objeto existente. Para Hume, a ideia de causa não está implicada na de efeito: na percepção da qualidade de um objeto a que a imaginação outorga o papel de "efeito" de uma relação causal, nada há que indique que tal objeto foi causado por outro; do mesmo modo, a noção de "causa" tampouco é dada na qualidade do objeto ao qual a mente atribui essa condição. Nem a função de efeito nem a função de causa são intrínsecas aos objetos que a imaginação considera como tais. A relação de causalidade é subjetiva, concerne à perspectiva do observador, e não existe senão como ideia imaginária.

\section{III}

Contudo, se é possível conceber no primeiro momento que um objeto não existe para em seguida concebê-lo como existente, como se pode formar na imaginação uma ideia de causalidade? Ora, a causalidade não é uma relação objetiva entre as coisas, mas uma operação do entendimento, e, portanto, a inferência da causalidade não decorre da existência dos objetos em si mesma, mas da experiência de sua conjunção constante, sob cuja imagem eles se oferecem à percepção. Quando uma impressão se representa na mente, esta é naturalmente determinada a formar uma ideia mais viva dos objetos constantemente relacionados, pela experiência, a essa impressão. Uma impressão presente associa-se, na imaginação, à ideia reavivada por ela; sua imagem conjuga-se na mente com a ideia de um objeto com o qual ela está em conjunção constante na experiência. A inferência supera o dado do sentido e torna presente à imaginação algo que não é imediatamente presente à sensação e que não pode ser inferido 
apenas a partir da qualidade do objeto percebido. O sujeito, ao inferir, afirma mais do que lhe informam os sentidos: ante a impressão de um objeto, a imaginação, sem mediação cognitiva, associa logo a ela a imagem ou a ideia de um outro, cuja conjunção com o primeiro foi objeto de percepções passadas. Assim a apresentação do primeiro objeto à percepção é causa da reapresentação, na imaginação, da ideia de sua conjunção constante com o segundo.

A ideia de causalidade reproduz a imagem de uma conjunção constante, reavivada na imaginação pela sucessiva percepção de casos semelhantes na experiência. A uniformidade dessa conjunção e sua reiteração na experiência reforçam na mente a suposição de sua ocorrência futura. Esse conhecimento, aprendizado progressivo da semelhança dos casos de conjunção constante que se repetem na experiência, não constitui uma certeza, mas uma crença. Quando a mente oscila da ideia de um objeto à de outro, ela obedece ao princípio de associação de ideias, mas, à medida que dada associação se torna recorrente na imaginação em virtude da regularidade com que a conjunção constante se repete na experiência, a mente, afetada pela ideia de um objeto presente, será determinada a relacioná-la à ideia de um objeto ausente, a crer na existência desse último supondo-o ligado ao primeiro por uma conexão necessária. Essa ideia de conexão necessária não advém da uma impressão da experiência nem diz respeito às ideias relativas a cada um dos objetos distintos: ela se produz porque a presença de um deles, dada na forma de impressão numa experiência atual, abstrai a ausência do outro.

Nenhuma ideia nova, porém, pode ser derivada de casos repetidos de conjunção constante, pois as diferenças de tempo e espaço entre eles acabam por torná-los mutuamente independentes ou aleatórios. A repetição convertese em progressão, isto é, toma forma de uma memória acumulada, quando deixamos de considerá-la quanto aos objetos que se repetem para ter em conta apenas a sua influência no espírito do observador. Na experiência, o observador depara-se com sucessivos casos de conjunção constante, que variam no tempo e no espaço; a união desses casos no seu espírito, isto é, a associação desses casos a uma mesma ideia de conjunção constante, permite-lhe refletir sobre a experiência. Esse movimento reflexivo caracteriza o entendimento: para Hume, o entendimento é a mente qualificada pela experiência, afetada por uma impressão de reflexão que apresenta o tempo sob a forma de passado; a imaginação é a mente mesma, mas considerada no seu modo de refletir o tempo como um futuro determinado por uma espera, por uma crença na previsibilidade.

A união, na mente, de casos repetidos de conjunção constante produz outra impressão: a impressão da repetição, isto é, a impressão de que o evento 
de uma experiência presente coincide em seus objetos e relações com o evento de uma experiência passada. Essa impressão de repetição não diz respeito a uma enumeração de casos, mas à consideração de um conjunto de casos na sua globalidade. A relação que ela reflete não é a que une os termos de cada conjunção constante, mas a relação entre essas conjunções mesmas, percebidas como eventos uniformes, unidades idênticas de causa-efeito que remetem umas às outras como sobreposições, na memória, de um mesmo caso de conjunção constante. Mas essa relação que a mente identifica entre pares repetidos de causa-efeito é exterior a seus termos e não se explica por eles: isso quer dizer que casos anteriores e posteriores de uma conjunção constante apresentamse, na experiência, como objetos singulares de percepção, e é apenas pelo movimento de associação de ideias que eles se unificam na imaginação. Cada caso de conjunção constante produz uma impressão distinta e configura um dos termos da repetição, mas a ideia de conexão entre os eventos causais, separados no tempo e espaço, não corresponde a uma impressão distinta. $\mathrm{Na}$ frase "O sol nascerá amanhã porque todos os dias até hoje nasceu", o conectivo "porque" não se reporta a nenhuma impressão: o que produz a ideia de que a posteridade liga-se à anterioridade na experiência e determina a mente a vagar de um objeto a outro, projetando o passado sobre o porvir, é apenas a crença na previsibilidade. A imaginação opera pela crença quando, determinada pela experiência reflexiva, transita da impressão presente de um objeto à ideia de outro, ausente. Para Deleuze, ${ }^{9}$ a crença encontra sua lei na causalidade na repetição de casos de conjunção constante presenciados na experiência, e une, por uma relação causal imaginária, uma ideia vívida a uma impressão presente. A imputação de causalidade aos casos de conjunção constante constitui o hábito, sob cuja influência a imaginação tende a prever o futuro de acordo com o passado.

Se crer é inferir com base na experiência, quando esta toma a forma de um hábito, a crença conserva-se nos limites do entendimento e propõe-se, na imaginação, como ato de conhecimento. Para Hume, "crer é sentir uma impressão imediata dos sentidos ou uma repetição dessa impressão na memória; é a vividez dessa percepção que constitui o primeiro ato do juízo e estabelece o fundamento do raciocínio que formamos com base nela ao traçarmos relações de causa e efeito". ${ }^{10}$ A regularidade da experiência permite-nos tirar conclusões que excedem as percepções presentes; pela crença nascida do hábito progressivamente constituído, convertemos a mera repetição de casos 
de conjunção constante em uma produção de inferências de probabilidade. A passagem do hábito - que abrange, na mente, a união dos casos de conjunção constante na experiência — à crença — ato próprio de conhecimento - é comparável à transição hegeliana da quantidade à qualidade, pela qual simples modificações quantitativas se transformam, em dado momento, em diferenças qualitativas: produzida por certo número de impressões acerca de conjunções passadas, a crença não acrescenta nada à ideia, mas altera o modo pelo qual a mente a concebe, dotando-a de maior força e vividez.

A ideia de causalidade sob a qual a mente relaciona os objetos é imaginária, subjetiva, e não corresponde a qualquer conexão natural discernível pela experiência: é a experiência passada que nos informa dos padrões de conjunção causal constantemente observados e nos habitua a supor ou inferir os termos de uma conjunção a partir da percepção de um deles. A crença na causalidade é a primeira etapa da cognição e denota a impossibilidade prática do ceticismo absoluto. Ela é, em Hume, o critério de verdade da ciência da natureza humana.

\section{IV}

A experiência induz-nos a esperar efeitos semelhantes de causas semelhantes. Mas, conquanto constitua o mecanismo operatório da imaginação, o princípio da associação de ideias não explica por que uma dada impressão evoca uma dada ideia; noutras palavras, a regra associativa da imaginação explica seu modo de operar com as ideias, mas não o conteúdo qualitativo das ideias associadas ou o critério de semelhança que as relaciona. $O$ único princípio capaz de justificar os conteúdos singulares do pensamento é a afetividade. As paixões afetam-nos quando o objeto que elas envolvem é de natureza semelhante à nossa. Na dinâmica afetiva, a afinidade entre as naturezas humanas faz presumir uma correspondência entre os estados afetivos; segundo Hume, somos guiados por uma espécie de pré-sensação que nos adverte do que se passa com os outros a partir daquilo que sentimos imediatamente em nós mesmos. Reside nisso o fundamento da teoria humiana da simpatia.

A simpatia diz respeito ao "eu", na medida em que o consideramos objeto afetivo para um "outro". A intersubjetividade tem lugar porque as naturezas humanas são semelhantes entre si: tal semelhança apresenta-se a nós, pela experiência, como ideia, e não como dado inato do espírito. Além da regra da associação de ideias, o que assemelha os homens entre si é o fato de perceberem uns aos outros como objetos afetivos. Essa afinidade de natureza é antes sentida que pensada, ou seja, precede à consciência que formamos a seu 
respeito e não depende dela. Quaisquer que sejam as paixões que nos impelem à ação, o princípio que as anima é a simpatia.

Por efeito da simpatia, pela suposição da afinidade dos estados afetivos humanos e pela reflexão, a partir da experiência, dos casos de conjunção constante de motivos e ações, é-nos impossível não formar uma ideia da intenção que imaginamos causar uma ação alheia e exprimir, ao percebê-la, um juízo moral. A simpatia induz o sentimento de moralidade que nos leva a considerar um caráter humano geral sem relação a interesses particulares. Mas a consideração desse caráter geral, da perspectiva daquele que julga moralmente, é parcial: um homem sempre pertence a uma família, a uma comunidade, a um universo afetivo definido, e não pode ser concebido isoladamente. Segundo Hume, cada homem tem uma posição particular quanto aos demais, posição passional, e o senso de dever à luz do qual se orienta no universo moral e julga os demais obedece ao curso de suas paixões. Mas a simpatia implica então uma diversidade moral, signo da própria diversidade das paixões, das relações afetivas específicas presentes na alma dos homens. Essa concepção moral coloca, então, uma questão política: como indivíduos afetados de paixões parciais podem constituir uma sociedade?

Na medida em que é parcial, a simpatia é uma paixão antissocial; portanto, o problema da sociedade passa a ser o da sua integração, o da conciliação das simpatias - a unificação das morais parciais ou subjetivas em uma moral social. A criação de um mundo moral objetivo coincide com a fundação de uma totalidade política, assim como a instauração do princípio artificial de justiça, em torno do qual o mundo moral se ordena, reclama, para sua eficácia, a instituição de uma autoridade capaz de julgar. Segundo a interpretação de Deleuze, ${ }^{11}$ a realidade do mundo moral é a constituição de um todo social, do qual a justiça é o princípio ordenador que harmoniza artificialmente simpatias ou paixões naturalmente diversas. A relação entre motivos e ações é compreendida como relação de causalidade, mas, nas ações determinadas pelas paixões, a causalidade toma a forma de uma relação de meios e fins, visto que o efeito esperado pelo agente é a obtenção de um bem desejado. A origem motivadora das ações humanas constitui sua própria finalidade: o agente deseja que se produza um efeito, cuja causa se esforçará por buscar. A finalidade propulsiona a ação: a mente é ativada, e a paixão põe a razão em marcha. A noção de bem desejado, contudo, vincula-se estreitamente à moral passional, à parcialidade afetiva dos homens, e contrapõe-se ao 
princípio de justiça fundador da moral social. Para evitar o confronto entre parcialidades afetivas e perspectivas morais subjetivas, o problema moral resolver-se-á pela instituição de um princípio moral objetivo — a justiça que estruturará totalidade política a fim de fazer convergir a um mesmo fim os interesses particulares. A satisfação dos fins — desejos e paixões — cumprirse-á então dentro de um sistema definido de meios de ação, de mecanismos estáveis e comuns, independentes das intenções de cada agente. Tais meios constituirão, em si mesmos, finalidades sociais objetivas, que orientarão os agentes na busca de seus fins parciais subjetivos: consistirão em regras de ação socialmente válidas, em normas morais, em valores. A ação moralmente virtuosa conformar-se-á a esse valor artificialmente instituído e será a um só tempo uma ação justa e politicamente obediente.

A sociedade é fundada para satisfazer a natureza; o instinto reclama sua instituição: a tendência que nos compele à realização dos desejos e interesses que formam nossa natureza afetiva exige o sistema cultural dos meios através dos quais a moral social nos permite dar curso positivo às nossas paixões e simpatias sem nos opormos uns aos outros. De outro modo, os inevitáveis conflitos que decorreriam da parcialidade das simpatias e da intemperança das paixões logo eliminariam da vida humana qualquer estabilidade. Esse momento hobbesiano da teoria política de Hume não será contornado por um pacto conservador dos direitos preexistentes, mas por uma convenção que irá criar esses direitos sem negar a natureza passional e moral do homem. A sociedade nasce, portanto, como um artifício que ilude nossas determinações naturais, realizando-as pacificamente ao mesmo tempo que as reprime. $\mathrm{Na}$ fundação da ordem social, as possibilidades de expressão da necessidade (desejo) e da natureza (sentimento moral) coincidem com os limites assinalados pela justiça (instituição) e pela cultura (convenção): a forma de satisfação das tendências naturais dos homens é determinada pelo princípio de justiça que organiza o sistema de meios morais de ação. Esse princípio é estabelecido não em nome de uma razão superior e transcendente, mas em virtude de sua utilidade social, isto é, da percepção de que a conservação da sociedade é útil à natureza humana.

Instituída por uma convenção ditada pela utilidade, a sociedade organiza sua própria ficção, cria para si uma segunda natureza, sistemática, total, que se superpõe à primeira, caótica, fragmentada. A eleição de um princípio de justiça convenciona a identificação artificial das morais parciais, mas sua eficácia depende da conservação de um espírito social de obediência, tarefa que toca às autoridades políticas, aos governantes. $\mathrm{O}$ exercício do poder visa a manter viva nas imaginações a crença de que o Estado assim fundado é objeto de 
um interesse e de uma utilidade em que convergem todas as paixões parciais. Como governar um homem é induzi-lo a praticar uma ação, a dominação política deve recair principalmente sobre as paixões; contudo, em vez de oprimi-las mediante restrições inteiramente contrárias à natureza humana, o que seria insensato e vão, o político aproveita-se delas, dirige-as por certos meios à consecução de determinados fins, institui, pela lei, vias morais de realização das paixões. Isto faz do legislador o moralista por excelência.

Deleuze aponta que, para Hume, a moral é fundada pelas paixões: o artifício é produto da natureza humana. Em vez de situar a dualidade do sistema humiano na oposição entre natureza e artifício, ele a estabelece entre o conjunto da natureza, que abarca o artifício, e a mente afetada por esse conjunto. A natureza não é uma totalidade sistêmica, mas uma coleção de acasos singulares, aos quais a imaginação, pelo mecanismo de associação de ideias e pelo hábito formado na experiência, confere sentido e finalidade. $\mathrm{Na}$ vida social, a imaginação sobrepõe, ao fluxo de impressões desconexas que afetam a mente, uma totalidade esquemática constituída de modelos estáveis de meios e fins, de causas e efeitos, padrões de conjunção constante que simulam regularidade não apenas nas relações humanas como também nos processos da natureza. O hábito é uma segunda natureza sob o efeito da qual supomos tanto a continuidade dos processos gerais da existência social e natural - "as leis de hoje serão válidas amanhã", "o sol nascerá amanhã como hoje" - quanto a duração de nossa própria vida. Em função do hábito, da crença na previsibilidade, podemos cultivar planos e expectativas.

A instituição de regras de justiça, normas de associação que ensejam repetições de modelos de conduta, consolida os hábitos sociais e, plasmando o futuro pelo passado, produz a própria conservação da ordem política. A imaginação e a crença imprimem ao mundo e à vida social uma previsibilidade artificial mas eficaz, cuja ausência não nos permitiria distinguir os meios de ação que serviriam a nossos fins. Por isso a sociedade é útil: mercê da convenção que a institui, podem os homens moldar o mundo exterior segundo as associações das ideias na imaginação e outorgar constância e uniformidade à sucessão de suas próprias impressões. Mas a relação causal atribuída pela imaginação aos casos de conjunção constante entre atos e intenções recebe ainda o acréscimo de um terceiro termo: as circunstâncias de tempo e lugar. Estas explicam a diversidade que, a par da regularidade, se observa na prática humana. A história das sociedades é a história dos sistemas de crenças cristalizadas, uma história das diferentes convenções de justiça estatuídas em proveito da harmonização de paixões naturais invariáveis: em Hume, a história é a verdadeira ciência da motivação humana, ciência que mostra como 
os homens, sob circunstâncias morais e sociais diversas, julgam uns aos outros por um critério artificial, fundado numa ideia convencionada de justiça, e por um critério natural, determinado pela associação de causa e efeito com que relacionam os motivos e as ações de seus semelhantes.

\section{Referências}

DELEUZE, G. Empirismo y subjetividad: la filosofia de David Hume. Barcelona: Gedisa, 1977.

HUME, D. Tratado da natureza humana. Tradução de Débora Danowski. São Paulo: Unesp: Imprensa Oficial, 2001. 